\title{
Legal History Turns: Topics and Optics
}

\author{
Karen Schultz
}

\begin{abstract}
This article locates 'legal history turns' in the wider intellectual landscape of the proliferation of turns in the 20th and 21st centuries, and examines the tension between turns' diverse topics and optics. These 'optics' represent diverse historiographical and interdisciplinary perceptions that illuminate topics in law, legal scholarship and legal history. The article first 'defines' legal history turns, and then moves to consider how the increasing production of turns generates tensions not only between topics and optics, but between brighter views and darker visions of 'turn talk'. The potential of exploring legal history turns is endorsed by identifying how optics are generated from the topics of the 'Legal History Turns' Special Issue.
\end{abstract}

\section{Overview}

This examination, and the Special Issue that it introduces, explores legal history turns in a time of 'turn' controversy. In so doing, it argues for the value and optimism - that is, a 'brighter view' - of upholding diverse legal history turns, and eschews the pessimism or 'dark visions' ${ }^{1}$ exhibited by critics of proliferating turns. As idioms for change, legal history turns traverse various 'topics' and 'optics' or historiographical ways of perceiving - they illuminate contemporary directions in law, legal scholarship, and the interdisciplinarity of legal history. 'Turns' are literary or intellectual volte-faces that are meant to represent perceived new directions or deviations from an interpretation or practice. Legal history turns allow interpretations, re-interpretations, and re-appraisals of present law by offering historical analysis and by addressing the "problematic of past law in history's present ${ }^{2}$ - hence, they can offer insight as to how to position and understand future law. But turns can be controversial.

First, a point of context. This Special Issue grew from the running of the first Legal History Seminar Series, an initiative intended to assist in stimulating, or re-energising, interest in legal history in Queensland. ${ }^{3}$ The present Special Issue produces articles from six of the seven scholars of Griffith Law School's first Legal History Seminar Series; aspects of the seventh article were published elsewhere. ${ }^{4}$ During the Series, articles were

1 Julia Adeney Thomas, 'Not Yet Far Enough' (2012) 117 American Historical Review 794, 795.

2 Diane Kirkby, 'Introduction: Interdisciplinarity in the Study of Law's History' in Diane Kirkby (ed), Past Law Present Histories (ANU EPress, 2012) paragraph 4.

3 This first Legal History Seminar Series ran from 13 December 2011 to 13 December 2012, in Brisbane, Queensland.

4 Shaunnagh Dorsett, 'Travelling Laws: Burton and the Draft Act for the Amelioration and Protection of the Aboriginal Natives 1838 (NSW)' in Shaunnagh 
delivered orally in a public lecture setting by scholars highly-esteemed in legal history; each article was anchored by a topic in the form of a nominated legal history turn. While there was no suggestion that the turns were delineated by clear borderlines, each scholar principally focused on one turn qua topic. Their brief was wide, their discretion unfettered simply, they were to consider current or new directions in legal history within their allotted 'turn'. The Series' driver was the generation of broad engagement in legal history thinking.

To locate the Special Issue in the wider intellectual landscape, this article addresses the larger issue of the current critique of the proliferation (and then seeming supersession) of turns in the 20th and 21st centuries. This proliferation is variously characterised. Recently, it has been described as a tension between 'topics' and 'optics' - that is, the superfluous swelling or even spawning of mere 'topics' as opposed to the addition of valuable 'optics'. The notion of 'topics' describes the diverse array of 'historiographical markers' ${ }^{5}$ defining the timing of new turns, and the increasing assemblage of subject-matters or disciplines that are described as experiencing a 'turn'. The notion of 'optics' describes the illumination and 'brighter views' that turns can cast on the intellectual directions of particular subject-matters or disciplines, to offer new perceptions, understandings or interpretations. ${ }^{6}$ Yet one significant concern is that this marker of a 'turn' is so overused that it is not generating new 'optics' and ways of perceiving.

This article, the Special Issue's prologue, has three movements. First, it briefly 'defines' turns and legal history turns, adverting to contemporary debates on the dizzying proliferation of turns. Second, it moves to the tension between the 'topics' and 'optics' of turn rhetoric, positioning the turn within three characterisations of this tension that emerged from an American Forum contemporaneous with this Special Issue. In so doing, it synthesises the 'dark visions' and the 'light' or 'brighter views' of the generation of turns, but prefers the value of the latter. Third and finally, this article sketches how the Special Issue articles explore their allotted turn to illuminate legal history - it identifies 'optics' generated from the articles' turns and topics. Ultimately, a generative definition of turns is adopted here - that is, a definition endorsing, not foreclosing, the continuing value of a dynamic use and potentially volatile sense of legal history turns.

\section{II 'Defining' Turns}

An obvious initial question concerns what counts as a 'turn', let alone a 'legal history turn'. Put differently, can turns and specifically, legal

Dorsett and John McLaren (eds), Legal Histories of the British Empire: Laws, Engagements, Legacies (Routledge, 2014) 171.

5 American Historical Review Forum, 'Historiographical "Turns" in Critical Perspective: Introduction’ (2012) 117 American Historical Review 698, 698.

6 Catherine L Fisk and Robert W Gordon, 'Foreword: 'Law as ...': Theory and Method in Legal History' (2011) 1 University of California Irvine Law Review 519. 
history turns, be comprehensively defined? Should the notion of the 'turn' be open-ended or should it be collapsed to one turn? Moreover, is there value in turns and their proliferation?

In Western scholarship, the meaning of a 'turn' has evolved. Broadly, a 'turn' is a cognate for, or at least has a tethering to, the classical rhetorical tropes, and so has rhetorical potential - a potential, that is, for inventive connections that are persuasively and stylistically put. But equally, a 'turn' is understood in contemporary analysis as a 'pivot' and 'departure from well-trodden discussions and debates', ${ }^{7}$ and as a 'conversion' in intellectual history, shaping that history. ${ }^{8}$ Yet the last 30 years has seen a controversial surge in identifying new turns. This burgeoning 'discovery' of intellectual sea-changes has generated concern and disturbance - are certain turns being superseded or abandoned?

One answer is that turns continue to evolve, as three points instance. First, turns bear both a confined, and an extended, rhetorical sense: as confined figures, tropes or patterns (of speech, diction or expression) within an accepted grammar or rhetoric; or as extended dynamics, directions or structural shifts in intellectual thought and history. ${ }^{9}$ The confined sense was the initial conception of turns. However, in the extended sense that developed subsequently, turns began to signal radical redefinitions and reinterpretations of disciplines or conjoined disciplines (like the disciplines of law and history within 'legal history') - they were used to envision transformational impacts, and to denote the power, movement and liveliness of definitions and re-definitions. For instance, imperial and colonial scholarship ${ }^{10}$ has offered radical re-perceptions and explorations of the ambiguity of ideas and contexts (for instance, of institutions, instruments and decisions) previously investigated and 'explained' in law and legal history. So the definition of 'turns' has widened appreciably from the notion of a textual trope.

Second, turns can be compared to Kuhnian paradigm-shifts as a means of recognising revolutions in thought ${ }^{11}$ - they indicate new 'optics' or channels of perception. Like Kuhn's paradigms, articulations of turns are necessarily incomplete - their implications continue to unfold and be 'received'. ${ }^{12}$ But Kuhn's paradigm-shifts have been understood to direct

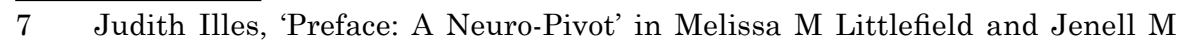
Johnson (eds), The Neuroscientific Turn: Transdisciplinarity in the Age of the Brain (University of Michigan Press, 2012) xi, xii.

8 Judith Surkis, 'When Was the Linguistic Turn? A Genealogy' (2012) 117 American Historical Review 700, 704.

9 David Armitage, Foundations of Modern International Thought (Cambridge University Press, 2013) 17ff, 'The International Turn in Intellectual History'.

10 Shaunnagh Dorsett and Ian Hunter (eds), Law and Politics in British Colonial Thought: Transpositions of Empire (Palgrave MacMillan, 2010).

11 Thomas S Kuhn, The Structure of Scientific Revolutions (University of Chicago Press, revised ed, 2012) 92ff, being Chapter 9, 'The Nature and Necessity of Scientific Revolutions'.

12 Richard E Palmer, 'What Hermeneutics can Offer Rhetoric' in Walter Jost and Michael J Hyde (eds), Rhetoric and Hermeneutics In Our Time: A Reader (Yale University Press, 1997) 108, 112. 
attention forward - they were used from the late 1930s by cultural historians qua 'paradigm-busters' ${ }^{13}$ to challenge assumptions and promote what was novel. Contrary to this, certain recent turn talk has 'directed attention backward' - it has focused on the supersession of turns in order to produce 'more comprehensive conceptual inventories, new waves of self-critiques'. ${ }^{14}$ As a refinement then, Cook suggests that turn talk should adopt a prospective 'forward' focus, to effectively escape questions of whether 'we' are beyond certain turns. Perl-Rosenthal affirms this practice of 'employ[ing] the language of turns prospectively'. '[U]sed retrospectively', the language of turns risks being simply 'a way of warehousing supposedly outdated concepts'. But '[u]sed prospectively', it organises trends, disciplines or fields, and assists their sharper focus and advancement. ${ }^{15}$

Third, turns have evolved by being liberally adopted in, and applied or co-opted to, a vast array of disciplines. While turn rhetoric began in the humanities and social sciences, turns today map a great assemblage of disciplines or domains as include architecture, geography, economics, anthropology, curation etcetera. Even the claim that scholarship travels 'beyond' a particular turn is a factor propelling the production, mix or even profusion of topics and optics.

\section{Generating Turns}

As optics or historiographical lenses to sharpen perception, turns have been recognised, expanded and 'generated' in 20th and 21st century Western scholarship. But the gradual recognition of turns has been overtaken by today's seemingly vertiginous numbers, and this has generated concern. Are turns invested with a 'life-span', or do they represent superseded 'events' or usurped 'moments'?

The generation of turns is relatively recent. Credited as the original populariser of the linguistic turn, Rorty, in 1967, first 'identified' the linguistic turn as a foundational 20th century sea-change or 'transformative historiographical moment'16 - in so doing, he popularised the recognition of language and discourse in framing understanding and identity. His identification of the linguistic turn was grounded on Hume's fork - Rorty explained that the turn redescribed the 'distinction between "relations of ideas" and "matters of fact" as the "distinction between "questions of language" and "questions of fact". ${ }^{17}$ Yet, as Surkis recognises, Rorty's identification had an ironic edge - he critiqued the linguistic turn's

13 James W Cook, 'The Kids Are All Right: On the 'Turning' of Cultural History' (2012) 117 American Historical Review 746, 748.

14 Ibid, $\mathrm{n} 7$ (my emphasis).

15 Nathan Perl-Rosenthal, 'Generational Turns' (2012) 117 American Historical Review 804, 813.

16 Armitage, above n 9, 18.

17 Richard Rorty, 'Science as Solidarity' in John S Nelson, Allan Megill and Donald N McCloskey (eds), The Rhetoric of Human Sciences: Language and Argument in Scholarship and Public Affairs (University of Wisconsin Press, 1987) 38, 47. 
so-called 'coherence' by underlining the incoherence of the diverse arguments of its proponents. ${ }^{18}$

Rorty's later recognition of the generation of a number of turns usefully illustrates (and, in his case, repudiates) the 'life-span' notion of turns. In 1984, Rorty acknowledged the multiplication of turns. ${ }^{19}$ When traversing 'four genres' of historiography in philosophy, ${ }^{20}$ he appeared to extend the linguistic turn by 'suggestively referencing' contemporary movements or re-conceptions of inquiry in the human sciences with a triad of turns "First, the "linguistic turn", then the "interpretive turn", and now the "rhetorical turn". ${ }^{21}$ But, while his 'suggestive reference' could be read as signalling a serial progression of turns and hence the limited life-spans of turns that serially succeed one another, a better interpretation does not suggest any 'assumption of succession'. ${ }^{22}$ For Rorty did not indicate that the interpretive turn had eclipsed or succeeded the linguistic turn, nor that the rhetorical turn had trumped or overturned the interpretive turn. Instead, as Palmer explains,$^{23}$ the three turns - linguistic, interpretive and rhetorical - could be understood to co-exist together, and to complement one another. Hence, the linguistic turn negated the notion of language's transparency - it 'revealed language as a conditioning matrix for all thought'. The interpretive turn re-conceived the notion of objectivity - interpretations were inescapably interpretations-of-interpretations in infinite regression. And the rhetorical turn clarified the 'pragmatic and interest-laden dimensions of speaking in inquiry' - objectivity is not useless, but 'radically incomplete'. With their different points of focus, these three turns could subsist together - one turn did not necessarily supplant another, or have solitary purchase.

Yet, the early generation of these three turns has been greatly surpassed by the contemporary proliferation of turns. It has been claimed that the language of turns has been so over-used that it merely denotes new 'topics', not valuable new 'optics' or perceptions. So, is there correlative value in this seemingly exponential increase in what is denoted a 'turn'? One answer is that the increase is merely 'faddish' - the formal

18 Surkis, above n 8, 705, reading Rorty's invocation of the 'linguistic turn' as ironic, ambivalent and qualified, for highlighting its proponents' fractious arguments, and resisting the linguistic turn's totalising claims.

19 Richard Rorty, 'The Historiography in Philosophy: Four Genres' in R Rorty, JB Schneewind and Q Skinner (eds), Philosophy in History (Cambridge University Press, 1984). See Surkis, above n 8, 705. See Gabrielle M Spiegel, 'Presidential Address; The Task of the Historian' (2009) 114 American Historical Review 1, 2, n 3 .

20 Andrea A Lunsford, Kirt H Wilson and Rosa A Eberly (eds), The Sage Handbook of Rhetorical Studies (SAGE, 2009) 26, n 2. Rorty's four genres differ relative to the historian's purpose: historical reconstruction; rational reconstruction/modern appropriation; doxography; and Geistesgeschichte.

21 Herbert W Simons, 'Preface' in Herbert W Simons (ed), The Rhetorical Turn: Invention and Persuasion in the Conduct of Inquiry (University of Chicago Press, 1990) vii.

22 Palmer, above n 12, 110.

23 Ibid, 111-112. 
act of declaring a turn simply nominates its existence, not its substance or value. But the issue of proliferating turns deserves greater attention, particularly in a Special Issue comprising a raft of turns.

\section{Proliferating Turns}

Recent debate addresses the value of 'proliferating turns'. This phenomenon refers to the continued generation of turns, whether in the sense of an increasing number of turns, or in the sense of increasing labels for derivative, related or linked turns. This growth has attracted concerns, but equally there are initial qualifications and caveats.

Simply by way of example, the growth of turns in the humanities and social science ${ }^{24}$ is illustrated by the following inchoate list of turns - a veritable cornucopia - in alphabetical order only: aesthetic; affective; archival; argumentative; biographical; bodily; constructivist; comparative; contextual; corporeal; cultural; deconstructive; discursive; global; haptic; iconic; ideational; ${ }^{25}$ identitarian; imperial; international; interpretive; linguistic; literary; material; narrative; normative $;{ }^{26}$ performative; postcolonial; post-modern; post-structural; practical; pragmatic; reflexive; rhetorical; visual; spatial; translational; and transnational. This adjectival diversity is by no means exhaustive - a recent blog lists 45 turns, supplemented by an additional three in comments. ${ }^{27}$

\section{A Concerns}

Concerns attach to the question of the intellectual value of proliferating turns, and here Kompridis is instructive. When discussing the aesthetic turn in political thought, he first lists a selection of humanities and social sciences turns - 'the cultural turn, the interpretative turn, the postmodern turn, the cognitive turn, the affective turn'. Kompridis then records the suspicion that newly-minted turns can signal intellectually-opportunistic publishing activity - that is, a 'fleeting academic fashion of academic opportunism [not] a genuine sea change'. ${ }^{28}$ One genuine sea-change was the 'so-called linguistic turn' - it 'originally marked a fundamental break with methodologies and ontologies that ... privileged the internal mental states of a disembodied knowing subject' for at least three centuries. ${ }^{29}$

24 Nikolas Kompridis, 'Introduction: Turning and Returning: The aesthetic turn in political thought' in Nikolas Kompridis (ed), The Aesthetic Turn in Political Thought (Bloomsbury, 2014) xiv.

25 Mark Blythe, 'Structures Do Not Come with an Instruction Sheet: Interests, Ideas, and Progress in Political Science' (2003) 1 Perspectives on Politics 695.

26 Steven Wilf, 'Law \Text\Past' (2011) 1 University of California Irvine Law Review 543,564 , noting the possibilities of the 'normative turn to history' deriving from historical jurisprudence and legal realism. $<$ http://MarkCarrigan.net/2014/07/13/can-we-have-a-turn-to-end-all-turns/>. The additional three turns were spectral, post-human and ecological.

28 Kompridis, above $\mathrm{n} 24$, xiv.

29 Ibid, xiv-xv. 
Given its derivation from various sources and time periods, the linguistic turn's potential for multiplication and variation has been acknowledged. ${ }^{30}$ But concerns with proliferating turns go beyond mere variation. It has been argued that, by announcing the 'birth' of a turn, authors may erroneously ascribe 'newness' to an existing phenomenon, or inadequately sketch its linkages or history. Moreover, it has been argued that, by ensuring the ubiquity of turns, authors may be diluting their power. ${ }^{31}$ To use Wilf's metaphor, the search for new topics has a James Dean-like 'young and the restless' quality - the 'intellectual vertigo' of passing existing turns resembles 'cruising down the road in search of the next big methodological approach'. ${ }^{32}$ Wilf's list of serial turns in this road proposes a long perspective - so, after the social history turn, the cultural anthropological turn, then the linguistic turn, then the global turn. This usefully underlines the sense of dilution and incoherence in the literature as there is no one notion or order of the serial progression and timing of turns.

\section{B Caveats}

However, two caveats apply to these concerns with proliferating turns. First, the connections between certain turns may reduce the sense of dilution - the array of topics may not seem so substantively or conceptually diverse. Turns may be derivative, related or linked. For instance, derivative turns are evident where 'parent' or umbrella terms (or turns) encompass or inspire various 'child' terms (or sub-turns). Related turns include the "well-known cognate "turns": the linguistic turn, the semiotic turn, the discursive turn'. ${ }^{33}$ And linked turns may overlap in relation to their common elements or resemblances. So, the linguistic turn overlaps with, or has been denoted as, the narrative, discursive or literary turn; it additionally exhibits links with the rhetorical or argumentative turn. ${ }^{34}$

30 Ibid, $\mathrm{xv}, \mathrm{n}$ 1. In Kompridis's account, the linguistic turn has at least three variants: (1) Herder, Harmann, and Humboldt; (2) Frege, Russell and early Wittgenstein; and (3) Saussure. In Surkis's account, the linguistic turn has three divisions/derivations: (1) Wittgensteinian-inspired ordinary language philosophy; (2) Saussurean linguistics; and (3) German hermeneutical traditions, sub-divided to the Gadamerian existentialist tradition, and the Habermasian Critical Theory tradition: Surkis, above n 8, 705ff.

31 Melissa M Littlefield and Jenell M Johnson, 'Introduction: Theorizing the Neuroscientific Turn - Critical Perspectives on a Translational Discipline', in Melissa M Littlefield and Jenell M Johnson (eds), The Neuroscientific Turn: Transdisciplinarity in the Age of the Brain (University of Michigan Press, 2012) 1,8 , commenting on neuro-turns, given the wide application of the prefix 'neuro' to various disciplines.

32 Wilf, above n 26, 563. In Wilf's account, the road-trip is like 'the young and the restless, a James Dean (Rebel without a Scholarly Pause) sort of academic discipline' where the global turn travels to borderlands, passes subalterns, and crosses boundaries.

33 Jason Glynos, 'The Place of Fantasy in a Critical Political Economy. The Case of Market Boundaries' (2012) 33 Cardozo Law Review 2373, 2399.

34 Palmer, above n 12, 111. 
Similarly, the material turn overlaps with, has been denoted as, the bodily, corporeal or haptic turn.

Second, the value of diverse articulations of turns may actually be promoted by the very complexity of intellectual and material landscapes. Two recent groups of turns illustrate this. First, discussing the international turn, Armitage recognises that turns are not synonymous or identical simply because they exhibit linkages or overlap. Referencing 'non-national approaches to history' in the form of international, transnational, postcolonial or global turns, he rejects any suggestion that historians' pursuits of these turns are 'identical in scope, in subject matter, or in motivation'. ${ }^{35}$ Second, discussing the newly-minted neuro-turn/s, Littlefield and Johnson support the recognition of distinct neuro-turns as would correspond to a complex web of distinct neuro-disciplines. Underlining that the prefix 'neuro' is so 'ubiquitous and diluted' that it lends itself to myriad interpretations, they indicate the value in specifying various types of neuro-turns. For the prefix 'neuro' 'signifies a hypothetical location' so chimerical that it fails to account for the countless translations and representations constructing the brain. ${ }^{36}$

It seems clear that it is not the proliferation of turns itself that is to be repudiated, but a lack of meticulously-researched, well-argued reasons for each new turn.

\section{V 'Defining' Legal History Turns}

So, when 'defining' turns generally, or legal history turns in particular, a complex response emerges. To the question of whether there is but one 'historical' or 'legal history' turn, the response is clearly 'no'. Obviously, the terms 'historical turn' and 'historiographical turn' are generics they signal a general move to diverse historical and historiographical approaches and analyses that interrogate diverse disciplines. As the 'historical turn in anthropology' ${ }^{37}$ and 'historiographical turn in international law'38 illustrate, 'history' is a corrective to a-temporal, a-historical

$35 \quad$ Armitage, above n 9, 18.

36 Littlefield and Johnson, above n 31, 8, n 14 for instances of 'neuro' prefixing 'common words', and 9.

37 Caroline B Brettell, Anthropological Conversations: Talking Culture Across Disciplines (Rowman \& Littlefield, 2014) 17-18, 173, n 6, recording that what anthropologists term a 'historical turn', historians term a 'cultural turn'. See Peter Burke, 'Civilizations and Frontiers: Anthropology of the Early Modern Mediterranean' in John A Marino (ed), Early Modern History and the Social Sciences: Testing the Limits of Braudel's Mediterranean (Truman State University Press, 2002) 123, 129.

38 Stephen Hobden, 'Historical Sociology: Back to the Future of International Relations?' in Stephen Hobden and John M Hobson (eds), Historical Sociology of International Relations (Cambridge University Press, 2002) 42. See John M Hobson, 'What's at Stake in Bringing Sociological Back into International Relations? Transcending 'Chronofetishism' and 'Tempocentrism' in International Relations' in Stephen Hobden and John M Hobson (eds), Historical Sociology of International Relations (Cambridge University Press, 2002) 3. 
or 'historiophobic'39 perspectives. The 'historical turn' has been applied to diverse content, methods, approaches and historical contexts, and itself links to a variety of turns. For instance, the cultural turn has been invoked in relation to "political history and diplomatic history, urban history and environmental history, Cold War studies and histories of consumerism'. ${ }^{40}$ In addition, diverse legal history contexts exhibit various turns. Hence, it is 'better for a variety of styles of history to coexist' ${ }^{41}$ - great explanatory power flows from variously interrogating historical shifts, turns and returns.

Additionally, legal history turns may be defined as 'returns'. Rabban's celebrated examination of the transatlantic 'turn to history in law'42 reveals the 'historical return' 43 to a forgotten, discounted connection between 19th century legal and historical thought. This prior connection between law and history ${ }^{44}$ had been dismissed by proponents of the "new "sociological legal history". ${ }^{45}$ In the accepted socio-legal narrative, it had been understood that formalism reigned during this time, despite 19th century American legal writing's incorporation of an explicit legal history, and despite legal policy's implicit grounding in historicist defences or critiques. Rabban's unearthing of the 19th century transatlantic 'turn to history in law' reveals a broad 'return' by the so-called 'new' 20th century sociological and legal history turns to the field of earlier turns. This claim has attracted controversy, ${ }^{46}$ and has impelled a symposium on the merits of Rabban's text, method and conclusions. That symposium was an occasion for Rabban himself to return to - and reconsider, review and refine - his text. As a result, the symposium revealed a profusion of methodological forms and approaches for constructing a (legal) 'historical turn'. ${ }^{47}$

There is then no unicity of turns or legal history turns - no mandate for a single turn only. Instead, turns are defined by a diverse mix of topics

39 Hobson, above n $38,5$.

40 Cook, above n 13, 755, n 33.

41 Peter Burke, Varieties of Cultural History (Polity Press, 1997) Chapter 12, in the first paragraph of 'Problems'.

42 David M Rabban, Law's History: American Legal Thought and the Transatlantic Turn to History (Cambridge University Press, 2013); Alfred L Brophy, 'When History Mattered' (2013) 91 Texas Law Review 601, 603ff.

43 Hobden, above n 38, 56, referring to 'pathways to the analysis of international processes', and the fact that historical turns featured in the discipline's development.

44 Ibid, 107. Rabban constructs this transatlantic historical turn from two AngloEuropean approaches: the German conceptual perspective combining historical research with deductive analysis; and an English empirical tradition combining historical research with inductive analysis.

45 David M Rabban, 'Reconsidering Law's History: A Response to the Symposium Comments' (2010) 1 Jerusalem Review of Legal Studies 106, 114.

46 See Brophy, above n 42, 604ff, referring additionally to even earlier turns to history in American jurisprudence.

47 Symposium on Law's History: American Legal Thought and the Transatlantic Turn to History in (2010) 1 Jerusalem Review of Legal Studies 72-136. See Rabban, above $\mathrm{n} 45$. 
and optics, and an 'interdisciplinarity', however described..$^{48}$ It is the characterisation of this diverse mix that is next examined.

\section{Characterising Topics versus Optics}

As mentioned, one way to reassess the concept of turns is to consider the topics versus optics tension - that is, the distinction between the profusion of topics versus the production of optics. As Wilder observes in 2012, 'disciplinary history today is distinguished by a proliferation of topical turns and a poverty of timely questions'. ${ }^{49}$ He identifies, as a concern, the 'yielding' or 'subsiding' of the 'new optics' of the linguistic and cultural turns to 'routine research topics that reaffirmed traditional historiographic assumptions'. ${ }^{50}$ This concern echoes Hunt's warning in 1989 against 'developing a cultural history defined only in terms of topics of inquiry'. ${ }^{51}$ For a 'cultural history defined topically' may degenerate or decline to an intellectual poverty - 'an endless search for new cultural practices to describe, whether carnivals, cat massacres, or impotence trials' ${ }^{52}$

Characterising turns as a mix of topics and optics was integral to reassessing historiographic turns in the 2012 American Historical Review Forum. There, authors examined 'turn talk' by proposing both 'dark visions' and, alternatively, 'brighter views', ${ }^{53}$ of three intersecting characterisations of turns. Using terms of negativity and in this sense 'darkness', Surkis and Wilder labelled the three characterisations of turns as 'straitjacketing', 'proliferation', and 'foreclosure'. The labels could be expanded respectively to describe the 'straitjacketing' of the 20th century's critical historical ferment to a 'single' turn, the proliferation and periodisation of turns, and the foreclosure effect of turns. The common thread of these 'dark visions' is the notion that turns obscure, stultify and foreclose history and ideas. Surkis and Wilder's conception of the three characterisations represent their dismay with current trends in historiographical turns.

By contrast, using terms of positivity and in this sense 'brightness', Cook and Ghosh's articles and Thomas and Perl-Rosenthal's comments offer a counter to the three characterisations of straitjacketing,, 'proliferation', and 'foreclosure'. Their contrasting labels resist these negative trappings and recognise the 'capaciousness', 'production', and 'rebirth' of

48 Brettell, above n 37, 1, referring to 'interdisciplinarity, cross-disciplinarity, multidisciplinarity, and transdisciplinarity'.

49 Gary Wilder, 'From Optic to Topic: The Foreclosure Effect of Historiographical Turns' (2012) 117 American Historical Review 723, 744-745.

50 Ibid, 723.

51 Lynn Hunt, 'Introduction: History, Culture and Text' in Lynn Hunt (ed), The New Cultural History (University of California Press, 1989) 1, 8. See Cook, above n 13, 767, n 78, recognising this. See Surkis, above n 8, 709-710, referring to Hunt's juxtaposition of a series of approaches.

52 Hunt, above n 51, 9. See n 27, referencing Stearns's 'centrifugal tendency' of 'topical social history'. Thomas, above n 1, 795 . 
turns, respectively - the authors remain conscious of the dangers of the negative characterisations, while recognising the positive trappings of turns. The common thread of these 'light visions' or 'brighter views' of turns is the value of a mix of topics and optics in a cast of historiographical turns - turns then are perceived to be at least 'contentiously productive'. ${ }^{54}$

To illustrate the shifting ground of the topics versus optics tension, the dark and light visions of the three characterisations are sketched, below, as intersecting claims predominantly in relation to two heavyweight turns - the linguistic and cultural turns.

\section{A 'Straitjacketing' Claim and Counter-claim}

The first claim and 'dark vision' of turns asserts that turns straitjacket and conflate. Specifically, the 'optics' afforded by turns are impeded by formulating or 'consecrating' the linguistic and cultural turns as coherent 'single' turns - these formulations straitjacket the complexity of turns, obstruct diverse approaches and trends, and ultimately preclude questioning of the canon. It has been argued that characterising a historiographical 'moment' as a 'turn' is problematic as it homogenises what is otherwise complex. ${ }^{55}$ As Surkis stresses, the 'linguistic turn' was actually neither a single turn, nor a coherent moment. ${ }^{56}$ The term has been co-opted as a 'moniker' or hegemonic narrative to represent an incoherent, unstable braiding of distinct strands of thought and methods of inquiry. ${ }^{57}$ Yet, while the term should actually indicate a 'discipline-wide moment of methodological ferment', its current formulation 'relegates it to the past and pre-empts contesting its implications and assumptions'. Surkis complicates, problematises and provincialises this formulation, to propose what she describes as a genealogical counter-narrative - her aim is to reinstall debates in diverse disciplines. ${ }^{58}$ For her 'dark vision' of turns is that 'turn talk constrains our vision of the historical and historiographical future'. ${ }^{59}$ Similarly, Wilder rejects any celebration of a methodological consensus attaching to the linguistic and cultural turns, or any perception that they are commitments to be 'relegated to the past as discrete and completed events' ${ }^{60}$ Instead, they are 'terms of convenience', or 'ambiguous analytic categories' that have frequently 'conflated incompatible intellectual currents'. ${ }^{61}$

As a counter to this, a light vision of turns dismisses the sense of this straitjacketing or conflation. The linguistic and cultural turns, as Cook records, can be understood to be capacious 'conceptual inventories' ${ }^{62}$

54 Ibid, 800, commenting on Ghosh, below n 66, 772.

55 Surkis, above n 8,712 .

56 Ibid, 718-719.

57 Ibid, 712 .

58 Ibid, 703-704, n 15.

59 Ibid, 705.

60 Wilder, above n 49, 745.

61 Ibid, 725-726.

62 Cook, above n 13, 753. 
embracing 'multitudes' - these multitudes include continuing or unfolding narratives, plural turns and disciplines and modes, and 'unresolved possibilities' (not 'consolidating agendas'). ${ }^{63}$ Put differently, the 'new' turn talk recognises that 'turns' comprise heterodox strands - so, turning, for instance, via 'literary criticism, British cultural studies, or anthropology' or 'gender theory or subaltern studies' or 'Geertz, Foucault, Williams or Derrida', or 'epistemological overlaps that produced common modes of questioning'. ${ }^{64}$ The 'new' turn talk recognises too that turning is inflected with diverse transatlantic emphases: speaking generally, where the Europeans were engaged early on with cultural issues of empire, the Americans researched market and consumptive cultures; and where the Europeans were centrally focused on class, the Americans examined race. ${ }^{65}$ Similarly, Ghosh rejects the straitjacketing of turns and its inevitability, 'argu[ing] for future possibilities particularly in remaining critical of imperialism and its hegemonies' ${ }^{66}$ In her account, straitjacketing describes how 'the linguistic and cultural turns in [their] postcolonial avatar were ahistorical, indifferent to historical change, and prone to 'story plucking,' 'time flattening,' and 'leapfrogging' in narrating historical events' ${ }^{67}$ A critical response to this straitjacketing was the archival turn, following '[c]alls for empiricism in the imperial turn'. ${ }^{68}$

\section{B 'Proliferation' Claim and Counter-claim}

The second claim or dark vision of turns is that the proliferation of turns and topics does not illuminate. Specifically, turn talk and notions of moving 'beyond' a turn have resulted in a proliferation of new turns as 'topics', but a paucity of 'optics', where optics denote new perceptions and the urgent contestation of basic categories. ${ }^{69}$ The argument is that, because this proliferation of turns and topics has not generated increased optics, it should be curtailed. For it misreads the 'temporal complexity of history and the historical production of time'.$^{70}$ Moreover, this 'periodising impulse' can result in 'confusion proliferating. ${ }^{71}$ In Surkis's account, turn talk's 'implicit temporality' postulates turns, but demonstrates both unsustainable conflation (in the linguistic turn), and proliferation (in the 'rapid succession of historiographical moments' ${ }^{2}$ ). Similarly, in Wilder's

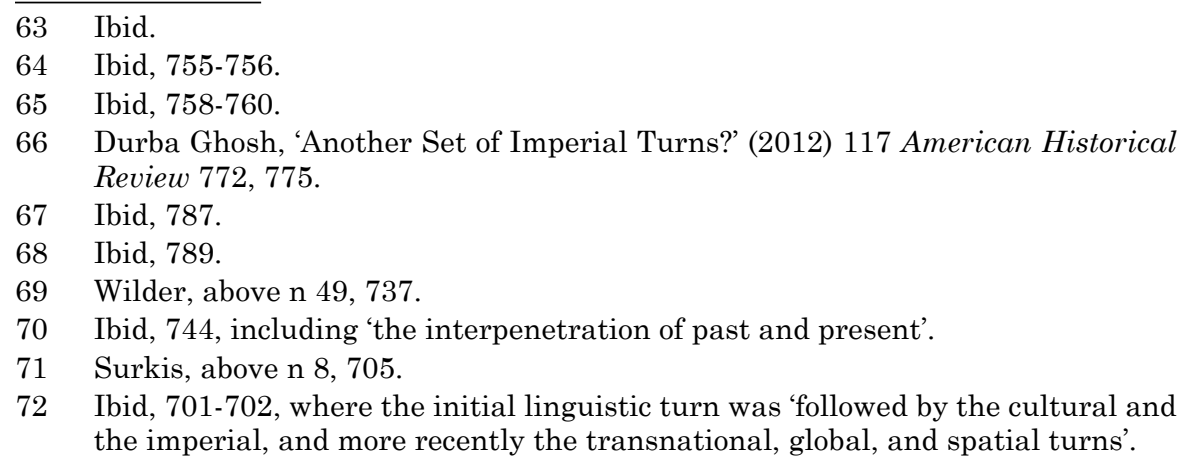


account, 'once optics are reduced to topics, new turns multiply without cost or stakes', and the 'proliferation of historiographical "turns"' results. He was not surprised that, as turns proliferated, historical debates concerning 'fundamental epistemological questions' ${ }^{73}$ declined.

As a counter to this, a brighter view of turns discounts the negative trappings of proliferation. Recognising one of the 1980's promises as the "push beyond "topics", Cook accepts the multiplicity and re-imaginings of turns as a more capacious field of "meaning making". ${ }^{74}$ For the concept of 'cultural turns' acquires 'additional semantic baggage' with 'each passing reference'. ${ }^{75}$ Moreover, contemporary turn talk's fast-moving narrative and discourse can operate on a higher metaphoric level - the cultural turn is not a 'ground-level concept' developed when doing cultural history, but a 'genealogical master-trope" ${ }^{76}$ substituting metonymically for cultural history, or synecdochically for longer conceptual histories. ${ }^{77}$ Similarly, Ghosh recognises the breadth and capaciousness of the historical field the implication is that a profusion of turns could helpfully follow. She is clear that the 'profusion of information, the spread of knowledge, people, cultures, and practices' in global and imperial networks illustrates that information is 'unmanageable by a single actor'. ${ }^{78}$ Ghosh does not, however, suggest a serial progression of turns: 'the language of the "new", "after", and "beyond" to describe historiographical turns seems premature'. ${ }^{79}$

\section{C 'Foreclosure' Claim and Counter-claim}

The third claim and dark vision of turns is that turn talk results in a 'foreclosure effect' - that is, devoting time in research to defining 'turns' limits or prevents greater analysis of historical fields. To illustrate this, Wilder questions, 'has the discourse of discrete and completed turns functioned to foreclose' critical debate in history? ${ }^{80}$ Surkis answers that, while this notion of the turn appears to 'signal innovation and renewal', recognising turns actually 'entails foreclosure' - defining turns in a generational model (as temporalised, single, fixed or completed) suggests the 'supercession of one disciplinary trend by another' ${ }^{81}$ In Surkis's account, turns ultimately must be illusory or 'purported'. ${ }^{82}$ Wilder does not reach this

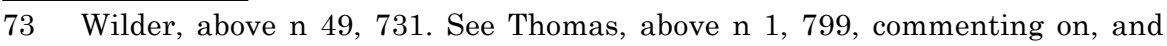
expressly adopting, Wilder - 'turners' longing for “"a new nominalism”, promote a methodological positivism and an "archival fetishism" more concerned with topics than optics'.

74 Cook, above n 13, 767.

75 Ibid, 755.

76 Ibid, 747.

77 Ibid, 749 .

78 Ghosh, above n 66, 793.

79 Ibid.

80 Wilder, above n 49, 723.

81 Surkis, above n 8, 702.

82 Ibid, 721, 722. See Thomas, above n 1, 796-798, reading this as the loss of the turn. 
ultimate conclusion, but does perceive the 'foreclosure effect' to be real and serious. Foreclosure signals the limiting or 'domestication of previous useful analytical openings or pathways, ${ }^{83}$ and results from accepting "completed turns, a new methodological consensus, and a professional reconciliation". ${ }^{84}$ Wilder's concern here is that the linguistic and cultural turns deserted useful 'structural analysis and societal explanation', ${ }^{85}$ and abandoned self-reflexive reflection on the currency and value of answering past questions. ${ }^{86}$

As a counter to this, a brighter vision of turns downplays or qualifies the foreclosure effect. Cook recognises a tension between retrospective and prospective views of turns - authors have inflected their turns as tales of retrospective disappointments ... [or] emphasised collective accomplishments, future possibilities' ${ }^{87}$ Dismissing notions that turns necessarily result in foreclosure, or that 'cultural history's swansong' has arrived, Cook counsels a three-fold rethink of the turn debate: first, one should consider the 'long-running plasticity of cultural history, a notoriously capacious category' that 'entailed a mobile unfinished project'; second, one should consider the parameters of 'what cultural history now is'; and, third, one should consider the 'semantics of our turn talk: our tendency to speak of the turn to culture'. ${ }^{88}$ For cultural history continues the on-going process of turning. ${ }^{89}$ Ghosh similarly qualifies the foreclosure effect by recognising that the imperial turn itself engages multiple, distinct historiographical turns - that is, 'the global, the postcolonial, and the archival'. ${ }^{90}$ By way of example, the archival turn did not inflict a 'closure, consolidating historians' access to "facts", but allowed the prospect of a new 'set of imperial turns' - for instance, the archival turn's engagement with the 'imperial/postcolonial turn' allows a 'return to archival research in a new spirit of interdisciplinary engagement and robust empiricism' ${ }^{91}$

\section{Balancing the Claims and Counter-claims}

These claims and counter-claims indicate the scale of the debate concerning the value of research on (legal history) turns. Dark visions of turns perceive and warn against the negative trappings of 'turn talk' and the stultifying effects of the generation of multiple turns and topics. By contrast, light visions of turns confirm that turns offer illumination and dynamic optics, and 'recast] the larger enterprise'. Light visions support multiple 'turns' and the practice of 'turning', as opposed to a singular 'turn'

$83 \quad$ Wilder, above n 49, 723, 728, 733, 740.

84 Ibid, 724 .

85 Ibid, 730 .

86 Ibid, 742, observing that this is the reflection and self-reflexive questions 'foreclosed by the post-turn consensus'.

87 Cook, above n 13, 757.

88 Ibid, 769-770 (original emphasis).

89 Ibid, 771.

90 Ghosh, above n 66, 773.

91 Ibid, 790. 
in the past tense - they support a 'more compelling cultural turn: beyond the generational we'. ${ }^{92}$

As a middle road between the negative and positive characterisations of turns, 'turn talk' clearly has the potential to generate a valuable dynamism. Admittedly, there is a shifting ground too: the practice of homogenising intellectual history supersedes or conflates turns; but the practice of periodising intellectual history produces or proliferates turns (that are then superseded, or conflated). Hence, new turns have occasioned or engineered the expiration of the 'period' of old turns and, due to claims of travelling 'beyond' the old turns, ${ }^{93}$ 'ideas of succeeding - and competing - historiographical turns have proliferated' ${ }^{94}$ Ultimately, shades of grey feature. For instance, even the authors of the 'dark visions' - Surkis and Wilder - offer brighter views on useful pathways for critical history although, on Thomas's reading, neither actually has a 'fully productive' vision of turns. ${ }^{95}$

This article adopts the position that balancing the claims and counterclaims best results in a 'revised language of turns'. ${ }^{96}$ Accepting the light visions of turns does not mean that the warnings of the dark visions go unheeded. In fact, it is important to acknowledge the rich nature of the debates. For the practice of turning can be 'framed within a non-supersessionist account of generational change: as a process of reinvention and reformulation ..., not a wholesale replacement', and not as 'intellectually barren reversals and re-reversals' ${ }^{97}$ Collectively, turns assist in answering a larger question key to legal history and to 'turn talk' - '[h]ow should we understand the relationship between thematic shifts and theoretical or epistemological reorientation?'98 Turns, then, are a 'gradual process' imagined as a form of cruising, not a 'sharp about-face ... lead[ing] only to dead ends'. ${ }^{99}$ They can be understood as expressive drivers to progress innovative and ultimately helpful ways to understand past, present and future law. And, as legal history turns have potential to critically consider law, they may assist in law's amelioration, negotiation and reform.

\section{ApPlying Topics AND Optics}

As mentioned, this article recognises that the 'dark visions' of turns ${ }^{100}$ sound a cautionary note, but does not understand that they quench

$92 \quad$ Cook, above n 13, 771.

93 Victoria E Bonnell and Lynn Hunt, 'Introduction' in Victoria E Bonnell and Lynn Hunt (eds), Beyond the Cultural Turn: New Directions in the Study of Society and Culture (University of California Press, 1999) 26, implying that 'beyond' is not a 'jettisoning' of insights, but a continuity promoting 'new directions' and a 're-examination and re-configuration' of the social.

94 Surkis, above n 8, 701-702.

95 Thomas, above n 1, 795.

96 Perl-Rosenthal, above n 15, 805.

97 Ibid, 813.

98 Surkis, above n 8, 715.

99 Perl-Rosenthal, above n 15, 813.

100 Thomas, above n 1, 795. 
the 'light' or 'optics' or 'future possibilities' of turns. ${ }^{101}$ For this reason, it prefers a 'light vision' of turns. In so doing, this article promotes an open-ended understanding of turns: as capacious concepts that articulate and generate continuing and unfolding perspectives; as plural 'turns' in the act of 'turning'; ${ }^{102}$ and as evolving, plastic vehicles that signal change and 'meaning-making'. One should then appreciate the multiple turns of legal history.

As this Special Issue's cast of turns illustrates, legal history turns are multi-faceted and multi-sourced - they exhibit a mix of topics and optics, and display diverse content, construction, methodology, evidence etcetera. Driving this Special Issue was a belief in engaging with this diversity.

\section{A Special Issue’s Impetus}

Together with this belief in the value of diversity, two impulses explicitly impelled the Legal History Seminar Series, that itself was the impetus for this Special Issue. ${ }^{103}$ First, the inaugural Organising Committee ${ }^{104}$ and successive Deans of the Griffith Law School ${ }^{105}$ were vitally interested in the future of engagement with legal history by the university and legal profession. The aim of the Series was to showcase legal history's 'interdisciplinarity', and to welcome all who were interested in its present and future significance. The thought was that, collectively, we would be participants in enlivening legal history interest in Queensland, in critically reflective directions. As free-standing legal history courses in Australian universities had reduced or disappeared in the latter stages of the 20th century, ${ }^{106}$ the Series was a gesture to legal history engagement, future pedagogical endeavours, and renewed interest in university-taught legal history. ${ }^{107}$

Second, the publication of articles delivered in, or inspired by, the Series contributed to renewed legal history engagement. The Series convenors ${ }^{108}$ had invited foremost scholars to each critically reflect upon

101 Cook, above n 13, 757; Ghosh, above n 66, 775.

102 Cook, above n 13, 770-771, discounting the tendency to refer to, for instance, 'the turn to culture' as if it was a homogenous turn.

103 The first Legal History Seminar Series ran from 13 December 2011 to 13 December 2012 , in Brisbane, Queensland; its inaugural seminar began at the conclusion of the 30th Annual Australia and New Zealand Law and History Conference, "Private Law, Public Lives", held on 12 to 13 December 2011.

104 The Legal History Seminar Series Organising Committee comprised Professor William MacNeil, Her Honour Judge Fleur Kingham of the Queensland District Court, Professor Andrew Buck, and its chair, Dr Karen Schultz. The Honourable Justice Susan Kiefel AC of the High Court of Australia graciously accepted the Committee's invitation to act as the Series Patron.

105 The successive Deans were Professors Paula Baron and William MacNeil.

106 Horst Lucke, 'Legal History in Australia: The Development of Australian Legal/ Historical Scholarship' (2010) 34 Australian Bar Review 109.

107 Douglas Harris, John McLaren, W Wesley Pue, Simon Bronitt and Ian Holloway, "CCommunity without Propinquity" - Teaching Legal History Intercontinentailly' (1999) 10 Legal Education Review 1.

108 The convenors were Professor William MacNeil and Dr Karen Schultz. 
a 'turn' that was relevant to legal history. With credentials well-known in Anglo-Canadian academic arenas or in the Australian judicial arena, each participant focused on one topic qua turn. In the Series, they delivered an article to an audience of judges, practitioners, academics, students and the interested public. In this Special Issue, either the Series article of each participant has been published, or a new article that was inspired by their allotted turn has been produced.

\section{B Special Issue’s Topics and Optics}

The authors' pursuit of the Special Issue's list of topics has clearly produced 'optics' or illumination. Simply by way of example, the mix of topics and optics includes examinations of newer turns (McLaren's comparative turn), older turns (Finnane's narrative turn), 'doctrinal' turns (Crofts's 'identic turn', and Gummow's 'constitutional turn'), and 'reviewed' turns (Saunders' re-telling of his 'biographical turn', and Phillips's examination of the 'end of turns'). The legal contexts are diverse, and include principal focus on British empire and colonial law (McLaren), early English law (Crofts and Saunders), Australian law (Finnane and Gummow), and Canadian law (Phillips). Additionally, the articles reveal multiple turns - whilst examining their allotted turns, a number of articles engaged variously with archival, imperial/postcolonial, or comparative turns.

To instance the articles' mix of 'topics' and 'optics', each article is denominated below in terms of its allotted turn. The list simply follows the order of 'turns' in the Legal History Seminar Series - it begins with McLaren and concludes with Phillips.

McLaren's larger work on the comparative turn invites 'comparisons and contrasts between jurisdictions in the Empire', and expressly intersects with the turns to critical geography and space. ${ }^{109}$ The Legal History Seminar Series had opened with his inaugural seminar - complete with song, he declared the 'coming of age' of Australian-Canadian legal history and of engagement in comparative scholarship. In this Special Issue, McLaren examines the history of the British Empire's concept of the 'rule of law in discourse, rhetoric and action', a concept 'so freighted with diverse political, social and even economic baggage' that it seems chimerical in its imprecision and contingency. His major focus is this 'tensile notion' of the Rule of Law and its contested interpretations 'within British and colonial legal or constitutional thinking' at the hands of an ostensibly independent judiciary. Additionally, he considers the embedding of the Rule of Law and its operation not least 'as a tool in the suppression of competing legal cultures'. For a future research agenda, McLaren proposes the richness of these contested 'ideological and theoretical debates', and the 'rich terrain of evidence' offered by the comparative turn.

109 Shaunnagh Dorsett and John McLaren, "Laws, engagements, and legacies: the legal histories of the British empire - an introduction" in Shaunnagh Dorsett and John McLaren (eds), Legal Histories of the British Empire: Laws, Engagements, Legacies (Routledge, 2014) 8. 
Crofts's newly-coined identic turn moves to a distant time and location in England to describe the incomplete, inconsistent common law doctrinal change in accessorial liability. Her revisiting in this Special Issue of the analysis of Rex $v$ Saunders and Archer (1573), examines the early treatise writers' work in the 'fledgling concept of transferred malice', and accompanies her larger work and dissection elsewhere of the 'poisoned apple of malice'. ${ }^{110}$ Crofts defines her identic turn as 'the treatment by the courts and legal doctrine of accessories as identic to principals', and instances a 'jurisdiction of blaming' that was relevant to accessories and their 'shadow or parasitic form of liability'. However, as she observes, the procedural identic turn was historically 'reinforced by an absence of clearly articulated justifications for culpability for complicity'. The upshot is the identic turn's inconsistent appearance, and its fractured application to the '(mis)remembered' tragedy of a poisoned apple.

Finnane's narrative turn surveys a different criminal law fracture - the tragedy of not one but two seemingly-linked murder cases in 1898 and 1901, featuring indigenous and settler protagonists. This seeming link apparently 'rendered Mary Durack speechless'. Finnane situates the two cases within the 'two laws' scenario of settler/indigenous offending in colonial society. He juxtaposes the moral tale of the politics of prosecution with the contextualisation of the criminal law's application, and its displacement of Indigenous law. His narrative turn examines the construction of two legal narratives - one rendering guilt, and one promoting innocence - in order to better 'appreciate the ambition and limits of the criminal law in a colonial society'. Hence, he frames this particular legal history turn as integral to the 'pragmatic history of legal pluralism'111 - it revisions externalities and social and jurisdictional issues that 'the criminal law commonly ignores in its narrowing attention to what is justiciable'.

Gummow's constitutional turn unfolds too from this time of Federation but covers large terrain in examining the relationship between 'history at the end of the Empire and the development and operation of the Australian constitutional structure', as perceived in High Court cases. Revisiting the issue of continuity and change, ${ }^{112}$ Gummow illustrates how the Constitution's operation and unchanging text 'has been modified to adjust to the diminishing authority of the British empire and its institutions'. The constitutional turn is an evolving one. Gummow fastens on five vexed sub-issues as exhibiting a constitutional turn: 'international personality', concerning the lack of (inter)national autonomy in light of 'residual links [and] bonds of the British Empire'; 'the sovereign's authority', concerning the Constitution's 'limited hinge' for responsible

110 Penny Crofts, Wickedness and Crime: Laws of Homicide and Malice (Routledge, 2013) 63.

111 Heather Douglas and Mark Finnane, Indigenous Crime and Settler Law: White Sovereignty After Empire (Palgrave Macmillan, 2012) 3.

112 William MC Gummow, Change and Continuity: Statute, Equity, and Federalism (Oxford University Press, 1999) 'Introduction'. 
government; 'the Governor-General's powers', concerning the disputatious existence of reserve powers in light of the 'shift in the Imperial kaleidoscope'; 'legislative power', concerning Commonwealth legislation's implicit restraint in light of retained Imperial legislation; ${ }^{113}$ and 'judicial structure', concerning the High Court's slow progress to the 'apex of an integrated Australian court structure'. The richness of the shifting ground of the constitutional turn, and its relevance to the comparative turn, is expressly acknowledged by McLaren's introductory paragraph.

Saunders's biographical turn returns to the shifting ground of a distant time and location in England, to rethink both his former polemical conception of Lord Nottingham's life as a 'proto-seculariser', and his assertion of an 'epochal "secularising" shift' in English law following the religious civil conflict. ${ }^{114}$ His former account of Nottingham focused on 'drawing a political diagram, not on sketching a judicial life history with appropriate attention to historical context'. However, concerned with that account's 'under-exposure to the light of legal history', Saunders now 'recognises that a seventeenth century English judge's relation to religion was material to how [the judge] fashioned a persona for judicial office'. As a result, he recants his thesis that 'English law was reconstructing itself as "secular", and re-examines Nottingham's views (including Nottingham's reasons in Coke v Fountaine (1676)) by comparison with Sir Matthew Hale's views. Saunders ultimately offers four points of revision and two protocols for pursuing a biographical turn with respect to early-modern lives. Using the notions of 'office' and 'persona', he proposes a negative protocol to avoid anachronism, and a positive protocol to respect the historical dead by describing their life-histories in historically-contemporary terms that they could recognise.

Finally, Phillips's contextual turn and his repudiation of the 'end of turns' reinforces that, in a 'world of political and economic change', legal history matters. ${ }^{115}$ He develops one of McLaren's examples of a cultural context ripe for comparative analysis - the role of judges and judicial independence. In his exploration of 19th century judicial independence models in three British North American colonies, Phillips forecasts continued turns in legal history's future - not fundamental turnarounds in doctrine, but 'the turning of corners' to reach by-ways where there appear frequently 'surprising insights'. His 'turn to contextualism' examines judicial fealty and 'good behaviour' versus 'at pleasure' appointments, to illustrate how both contextualism (whether imperial or local) and complexity (whether principled or pragmatic) are at play. His sub-theme is the intersection of judicial tenure with financial independence - a contextual shift in focus

113 The aliens power has agitated research: Karen Schultz, 'Future Citizens or Intergenerational Aliens? Limits of Australian Constitutional Citizenship' (2012) 21 Griffith Law Review 36.

114 David Saunders, Anti-lawyers: Religion and the Critics of Law and State, London and New York (Routledge, 1997).

115 Jim Phillips, 'Why Legal History Matters' (2010) 41 Victoria University of Wellington Law Review 293. 
to money. His is an optimistic voice for continuing legal history turns, and the 'future of the past'. The diverse topics and turns of the Special Issue support this optimism.

\section{CONCLUSION}

To conclude, a turning to final acknowledgements and thanks is required. First, warmest regards to the contributors - who, metaphorically, are the real 'optics' of this Special Issue - for their patience and gracious cooperation as the project perambulated to completion. Second, sincere thanks to the Organising Committee and Patron for their continued enthusiasm for legal history's significance and for the value of public education. Third, bravo to Professor William MacNeil for stamping his inimitable style on the role of the Master of Ceremonies for each Series seminar, and for his vision in funding the Series and enabling its planning. Fourth, sincere thanks to Professor Paula Baron, the Editor of Law in Context during most of the project's progress, for her well-managed organisation of anonymous reviews and the minutiae of publication. Finally, deepest regards to the memory of the gracious and highly-respected publishing mentor, Christopher Holt, one of the foundation-publishers of Federation Press. This collection is dedicated, with our very great esteem, to Chris, whose passing during production was exceedingly sad and unexpected. His expansive interest in legal history turns and his encouragement were an initial important impetus for the Special Issue.

As a final word, this Special Issue is but one validation of the value of the continuing interaction of the topics and optics of legal history turns. The fact that the cultural turn is an 'increasingly viral concept' of 'current ubiquity' 116 instances the continuing production of ideas and critical dialogue in history's intellectual landscape. The fact of the passionate, carefully-constructed cases for 'dark visions' and 'brighter views' in the 2012 Forum evinces the continuing belief in the value of ameliorating the 'dark visions' of turns, and in remodelling turns. ${ }^{117}$ The fact that scholars continue to devote time to constructing topics and reasons for new, future or extended historiographical turns ${ }^{118}$ indicates enthusiasm for an enlarged engagement with turns. And the fact that this Special Issue's diverse topics (turns, contexts, concepts etc) captured audience interest when orally delivered, and have generated a wealth of extensive 'optics' or insights, reinforces the value of 'legal history' turns as 'fresh, exciting and inspiring ${ }^{119}$ intellectual pivots.

116 Cook, above n 13, 746.

117 Surkis, above n 8, 722, alternatively fashioning turns genealogically, and as 'specifically located, imaginatively cast, at once multiple, overlapping, and dynamic constellations'.

118 Thomas, above n 1, 796, 801ff; Perl-Rosenthal, above n 15, 806; Dorsett and McLaren, above n 109, 8-9.

119 Illes, above $\mathrm{n} 7$, xiii. 